\title{
Increasing the manufacturing efficiency of WAAM by advanced cooling strategies
}

\author{
Uwe Reisgen $^{1}$ (D) $\cdot$ Rahul Sharma $^{1}$ (D) $\cdot$ Samuel Mann ${ }^{1}$ (D) Lukas Oster $^{1}$ (I)
}

Received: 11 February 2020 / Accepted: 26 May 2020 / Published online: 9 June 2020

(C) The Author(s) 2020

\begin{abstract}
Wire- and arc-based additive manufacturing (WAAM) is a promising technology for large-scale additive manufacturing of metallic components. However, due to the high heat input by the electric arc, interpass cooling time decelerates the average manufacturing speed. Since future applications aim to the production of large structural steel components, the manufacturing speed is a key parameter to make WAAM usable for civil engineering. Within the scope of this paper, different process cooling strategies are weighed up against one another with regard to efficiency, impact on the process, as well as to the influence on the microstructure of the processed steel. For the thermal evaluation, welds on vertically placed plates were performed using the gas metal arc (GMA) process. As far as different cooling methods are concerned, the standard GMA process is carried out with water bath cooling, high-pressure air cooling and also with aerosol cooling. Temperature curves were determined using thermocouples which are dipped into the molten pool. The evaluation of the microstructure and the hardness is carried out by means of cross sections and Vickers hardness tests. The results show that aerosol cooling can be a promising addition to WAAM as it can be applied during welding and is capable to modify the $t_{8 / 5}$ time and, therefore, the mechanical properties of the steel.
\end{abstract}

Keywords Wire arc additive manufacturing $\cdot$ Shape welding $\cdot$ Solid freeform fabrication $\cdot$ WAAM $\cdot$ Aerosol cooling $\cdot$ Arc-based additive manufacturing

\section{Introduction}

Wire- and arc-based additive manufacturing is a promising technology for the small-series production of highly individualised large-scale metallic components. Some of the major advantages are the large amount of usable materials, the variety of welding processes available and the high deposition rate [1-3].

In the 1980s, power plant components made of creep-resistant steel with a structural weight of more than 225 tons have been additively manufactured, using submerged arc (SA) welding [4, 5]. Currently, the range of industrial applications covers the processing of expensive materials such as titanium alloys, nickel

Recommended for publication by Commission XII - Arc Welding Processes and Production Systems

This article is part of the collection Additive Manufacturing - Processes, Simulation and Inspection

Lukas Oster

oster@isf.rwth-aachen.de

1 Welding and Joining Institute, RWTH Aachen University, Pontstr. 49, 52062 Aachen, Germany base alloys and high alloyed steels, for example for aerospace and naval industries [6]. Recent research started to focus on lowalloy steels, usable for example in the civil engineering sector. Here, highly individualised construction nodes are manufactured using wire- and arc-based additive manufacturing (WAAM) [7]. The lower the material cost, the higher the manufacturing speed needs to be, to make the process competable to traditional manufacturing processes in terms of manufacturing costs. The manufacturing speed is mainly defined by the deposition rate of the welding process and the idle time that is necessary to let the workpiece cool down to the required interpass temperature [8]. Considering gas metal arc (GMA) welding, the deposition rate is directly linked to the heat input of the process. The higher the deposition rate, the higher the process power and therefore the heat input as well as the cooling time. This contradiction can only be solved by establishing highly efficient and scalable cooling strategies.

Two sections of the cooling curve from solidification of the material until reaching the required interpass temperature for continuing depositing the next layer are of special interest.

The first part is the high-temperature section from solidification until the stop of the most important phase transformations. 
The second part is characterised by the total cooling time until the required interpass temperature is reached and the deposition of the next layer can be performed. Depending on the solidification behaviour of the processed material, the cooling rate within the high-temperature range has a high impact either on phase transformations or on the grain growth. Either way, there is a direct impact on the mechanical properties of the material. An example is a high-strength fine-grain steel, which requires the $t_{8 / 5}$ time to be within a defined range to enable good mechanical properties [9]. Here a too low cooling rate can lead to a loss of tensile strength, while a too high cooling rate might provoke cold cracking. Another example could be ferritic stainless high chromium ( $\sim 17 \%$ ) steels, like SFA/AWS A5.9 ER430LNb. After solidification, those steels do not undergo any allotropic phase transformation during the cooling process, which is why they are highly prone to grain coarsening. Here, high cooling rates are required to keep the grain growth within an acceptable limit [10]. These examples show that the development of a cooling strategy does need to consider not only the increase of the manufacturing speed but also effects on the material properties.

Investigations regarding the influence of interpass temperature on the component properties were carried out by various research groups $[11,12]$. Besides the metallurgical effects, the interpass temperature also influences the risk of thermal overheating of the component as well as the size of the molten pool. This is the reason why it is beneficial to let the component cool down to a defined temperature before welding continues. Depending on the processed materials and the experimental set-up, interpass temperatures commonly are within the range from 50 to $120^{\circ} \mathrm{C}$.

First experiments about cooling strategies for WAAM were carried out by da Silva et al. [13]. Here, the effects of water bath cooling strategies were compared with uncooled welds. The whole component was stored in a canister which was filled with water. The water level was raised stepwise together with the welding layers, to keep the distance to the weld bead constant. The tests showed that the water bath cooling seems to be highly efficient for reducing the workpiece temperature rapidly after welding. However, as the water bath is difficult to handle, especially in multi-axis manufacturing systems with moving worktable, other cooling strategies could be of interest. A similar approach of cooling the component side walls but with a completely different cooling method was investigated by Li et al. [14, 15]. As cooling device, Peltier elements were attached to the sides of wall-shaped structures to achieve an active cooling effect. The evaluation of the cooling strategy was done by depositing single weldments on upwards positioned plates, to keep thermal condition constant and achieve a good contacting surface for the Peltier elements. However, the application on geometrically more complex components could be difficult.

Further investigations were performed by Hackenhaar et al., using an air jet cooling system [16]. Here, a high-pressure air jet was directed to the workpiece to cool it down during and after welding. To prevent disturbance of the welding process, the air jet was not directly aimed at the process zone but at a lower side of the manufactured wall-shaped structures. The results show that the effective reduction of the interpass cooling time was possible. Similar investigations were performed by $\mathrm{Wu}$ et al., using a $\mathrm{CO}_{2}$ jet instead of a high-pressure air jet [17].

Considering the effects of cooling rates on the mechanical and geometrical properties as well as on the manufacturing speed, efficient cooling strategies are highly important for the implementation of an efficient WAAM-based process chain. The cooling strategies, which were investigated till now, either are very efficient in terms of cooling performance but difficult to handle for manufacturing complex components or are not capable of in situ cooling during the welding process. The aerosol cooling strategy could be a solution for an effective highly controllable and flexible low-cost cooling method.

The following article compares three different cooling methods regarding their $t_{8 / 5}$ cooling times as well as the duration until a nominated interpass temperature of $100^{\circ} \mathrm{C}$ is reached. As the focus is on the general comparison of the cooling methods, process parameters and materials are not changed.

\subsection{Experimental set-up and experiments}

The experiments were performed by simulating the additive manufacturing of wall-shaped structures. To avoid long manufacturing time and to keep the thermal heat dissipation conditions constant, the welds have been performed on vertically positioned metal plates with the dimensions $300 \times 100 \times$ $10 \mathrm{~mm}$. Material wise, S355J0 (DIN EN 10025-2) structural steel was used for the substrate plate and EN ISO 14341-A G 3Si1 (AWS A-5.18: ER 70 S-6) as wire electrode for the GMA process. As cooling strategies are especially important for high heat input process configurations and high deposition rates, all the experiments were performed using a standard GMA process in spray transfer mode. Table 1 gives an overview on the most important welding parameters.

The GMA welding torch was positioned on a linear movement; the substrate plate was positioned as shown in Fig. 1a. To keep the welding conditions constant, even for the water bath welds, the ground contact was clamped directly to the substrate plates.

As measuring set-up, thermocouples of type $\mathrm{k}$ in a ceramic mantle were used in combination with a transient measuring system of the type Yokogawa DL708. The sample rate was $1 \mathrm{ks} / \mathrm{s}$ for reliable measuring the cooling rates by estimating the $t_{8 / 5}$ times. The duration of the measurements was $16.66 \mathrm{~min}$ to determine the time until the weld seam reaches the $100{ }^{\circ} \mathrm{C}$ interpass temperature as an indicator for the idle (arc-off) time of the manufacturing process. Thermocouple measurements were performed at the centre of the samples by sticking the thermocouples into the molten pool directly behind the welding process (Fig. 1b). After the thermal 
Table 1 Welding parameters that have been kept constant

\begin{tabular}{ll}
\hline Wire feed speed & $8 \mathrm{~m} / \mathrm{min}$ \\
Welding current & $185 \mathrm{~A}$ \\
Welding voltage & $27 \mathrm{~V}$ \\
Droplet transfer mode & Spray transfer mode \\
Travel speed & $40 \mathrm{~cm} / \mathrm{min}$ \\
Contact tip to workpiece distance & $15 \mathrm{~mm}$ \\
Shielding gas & EN ISO $14175 \mathrm{M} 12\left(2.5 \% \mathrm{CO}_{2}\right)$ \\
Electrode diameter & $1.2 \mathrm{~mm}$ \\
Electrode & EN ISO 14341-A G 3Si1 \\
Welding torch position & PA \\
Substrate plate & DIN EN 10025-2 S355J0 \\
\hline
\end{tabular}

measurements were concluded, a second welding was performed over the first half of the sample using exactly the same welding parameters and cooling strategy to evaluate the impact of the cooling on potential heat treatment effects.

The investigated cooling strategies can be divided into in situ process cooling and ex situ cooling. For in situ cooling, water bath cooling was investigated, as well as an aerosol cooling strategy. A schematic diagram of the cooling set-ups is shown in Fig. 2.

For the water bath experiments (Fig. 2a), the samples were placed in a container which was filled with water with a distance between water level and top side of the sample of $10 \mathrm{~mm}$. Before and after welding, the water bath temperature was measured. At the start of the welding experiment, the water temperature was equal to the room temperature of $20^{\circ} \mathrm{C}$.

The high-pressure air cooling (Fig. 2b) was performed by aiming an air pressure nozzle directly onto the workpiece. The air flow was started, directly after the welding ended, and was kept constant. The measured air temperature at the nozzle tip was $16{ }^{\circ} \mathrm{C}$. The operating pressure was 8 bar; the cooling was stopped as soon as a temperature of $24{ }^{\circ} \mathrm{C}$ was reached.

For the aerosol experiments (Fig. 2c), an aerosol nozzle, made of brass, was mounted on the linear movement, behind the welding torch. The spray angle of the nozzle was $80^{\circ}$. The nozzle was aligned, with the spray cone ending $40 \mathrm{~mm}$ behind the GMA welding arc. The total distance of the nozzle to the welding torch was $500 \mathrm{~mm}$, to keep negative effects through turbulent air near the shielding gas atmosphere low. The aerosol consists of a water air mixture. The operating pressure was 3 bar with a flow rate of $480 \mathrm{ml} / \mathrm{min}$. The cooling was manually stopped when the measurement spot reached a temperature of $22{ }^{\circ} \mathrm{C}$. For all cooling methods, the initial surface temperature of the base plate, as well as the interlayer temperature for deposition of the second weld seam, was kept constant at room temperature of $20^{\circ} \mathrm{C}$.

After the welding experiments were finished, the samples were analysed regarding their microstructure and the hardness along the weld beads. Therefore, cross sections were taken from the single layer welds as well as from the double layer welds. For the micro cross sections, the samples were etched, using a $10 \%$ aqueous nitric acid. Macro cross sections were prepared, using 3\% alcoholic nitric acid. Vickers hardness tests were performed centrically along the vertical weld seam axis, including the heat-affected zone.

\section{Results}

\subsection{Temperature measurements}

The results of the temperature measurements are presented in Fig. 3. The reference measurement shows the lowest cooling rate with an estimated $t_{8 / 5}$ time of $21 \mathrm{~s}$; after $700 \mathrm{~s}$, the temperature curve intersects the $100{ }^{\circ} \mathrm{C}$ line. Compared with the uncooled experiment, the actively cooled welds show higher cooling rates and reach the $100{ }^{\circ} \mathrm{C}$ line faster. The highest cooling rate is achieved with the water bath cooling. Here, the $t_{8 / 5}$ time is $7 \mathrm{~s}$, and the $100{ }^{\circ} \mathrm{C}$ line is intersected after $38 \mathrm{~s}$. The aerosol cooling and the high-pressure air cooling curves show similar values regarding the cooling rates. Here, the $t_{8 / 5}$ time is $12 \mathrm{~s}$ for both curves and the $100{ }^{\circ} \mathrm{C}$ line is cut after $75 \mathrm{~s}$ for the high-pressure air curve and after $63 \mathrm{~s}$ for the aerosol curve. In addition, an increase in temperature can be observed after the cooling was stopped, which was after $200 \mathrm{~s}$ for the high-pressure air and $169 \mathrm{~s}$ for the aerosol. This does not affect the estimated values for quantifying the cooling behaviour.

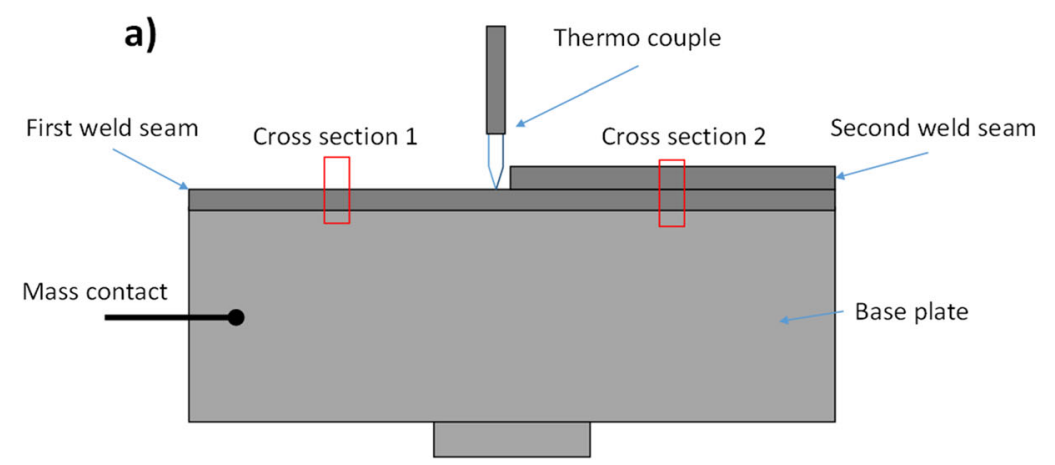

b)

Fig. 1 Schematic diagram of the measurement set-up (a) and picture of a thermocouple stuck in after the first weld (b) 


\section{a)}

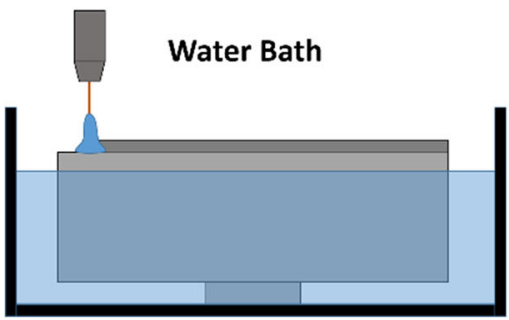

b)

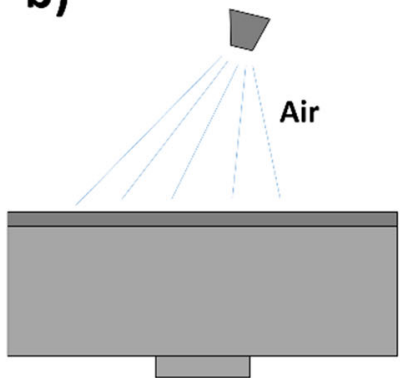

c)

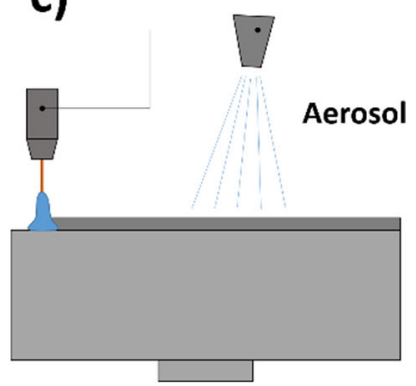

Fig. 2 Schematic diagram of the three cooling strategies. Water bath cooling (a) as in situ cooling method, high-pressure air (b) as ex situ cooling method during the idle time and aerosol cooling as in situ (c) method

Furthermore, the temperature curve of the aerosol cooling shows two anomalies: Firstly, the curve shows some unsteady drops in temperature; in addition to that, a plateau can be identified around the $100^{\circ} \mathrm{C}$ line.

\subsection{Microscopic analysis}

An overview of the single-welded samples is shown in Fig. 4. Since the high-pressure air-cooled welds have not been cooled in situ, during the welding process, they are not expected to be different to the uncooled samples in terms of microstructure. Therefore, the microscopic analysis is not shown here. It can be seen that the position of the GMA reference weld was not perfectly aligned, which led to an asymmetric weld seam shape. However, a comparison to cooling curves of better aligned, uncooled GMA welds showed no difference as far as the measured cooling rates are concerned.

The penetration depth is similar for all welds, whereas the water bath welds show a slightly higher penetration depth. Similarly, the fusion area lies with $33.1 \mathrm{~mm}^{2}$ for the reference weld, $32.5 \mathrm{~mm}^{2}$ for the aerosol-cooled weld and $33.5 \mathrm{~mm}^{2}$ for the water bath-cooled weld closely together for all three specimens. Especially for the aerosol weld and the water bath weld, the weld seam shape as well as the dendritic growth structure are very similar. None of the cross sections showed porosity or other weld defects.

Detailed microscopic pictures were taken along the vertical centre line of the samples (Fig. 5).

Looking at the secondary ferrite, a slight difference in the size of the dendrites is visible: While the uncooled weld shows the largest average dendrite size, the water bath-cooled welds show a much finer dendritic structure and the aerosol-cooled weld lies in between.

The double-welded samples for the aerosol and water bath welds are shown in Fig. 6. Here, no major differences regarding the solidification morphology are visible. The positions of the heat-affected zones as well as the penetration depths are similar.

\subsection{Hardness measurements}

Vickers hardness tests were made, both on the single-welded samples and on the double-welded samples, to show possible missing heat treatment effects. Figures 7 and 8 show the
Fig. 3 Time-temperature-curves of the three investigated cooling methods and the reference measurement without cooling. The horizontal red lines mark the characteristic temperatures $800{ }^{\circ} \mathrm{C}, 500{ }^{\circ} \mathrm{C}$ and $100{ }^{\circ} \mathrm{C}$
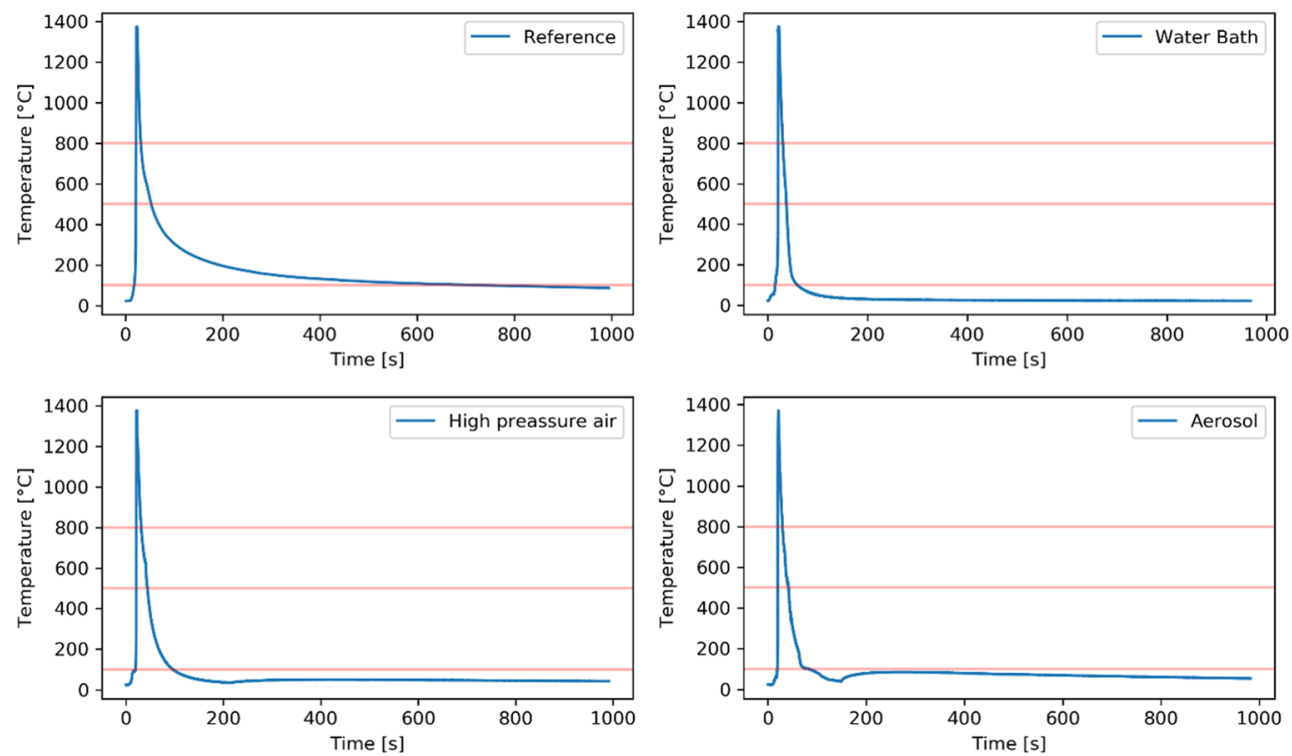

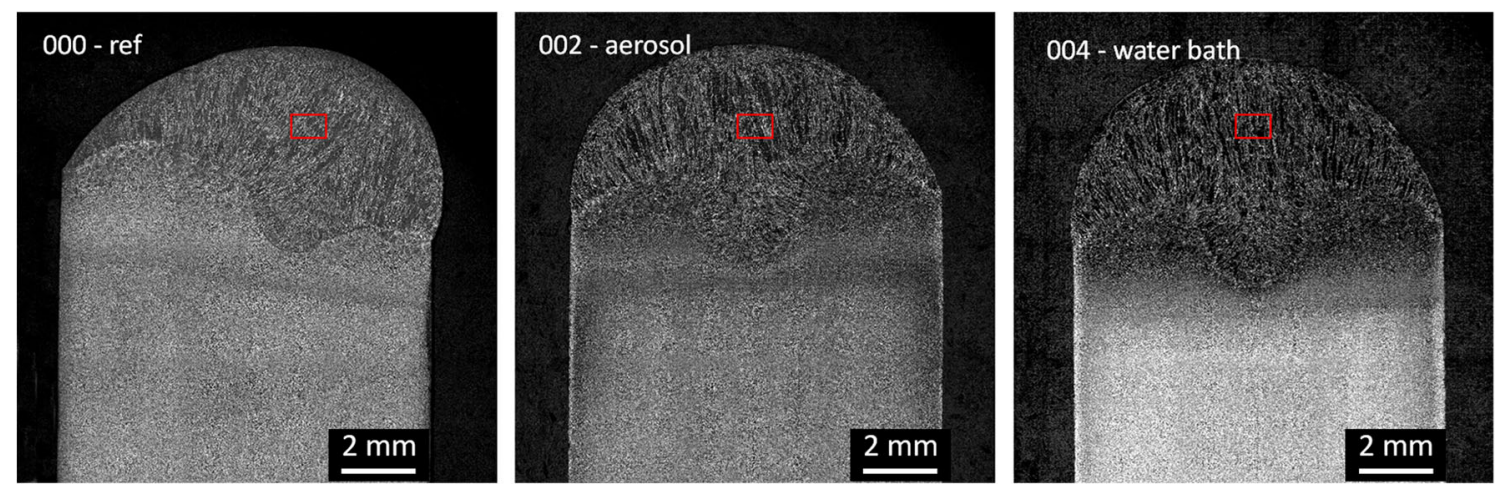

Fig. 4 Comparison of the macroscopic cross sections: uncooled GMA weld on the left, aerosol-cooled weld in the middle and water bath-cooled weld on the right. The positions of the microscopic pictures are marked in red

positions and results of the hardness measurements on the single-welded specimens.

All three measurement rows show a similar shape, containing a constant hardness in the weld material followed by a peak near the fusion line and a drop and raise of hardness along the heat-affected zone (HAZ). A difference can be seen in the average hardness, especially of the weld material. For the uncooled GMA weld, the average hardness is lowest (179 $\mathrm{HV}$ ), followed by the hardness of the aerosol-cooled sample $(196 \mathrm{HV})$ and the hardness of the water bath-cooled sample (232 HV).

Similar results can be seen for the double-welded samples (Fig. 9). As the total amount of weld material is larger, the characteristic locations of fusion line and HAZ are moved to the right. One difference shows the hardness curve of the water bath-cooled sample. Here, the average hardness of the weld material is lower, compared with the single-welded sample.

\section{Discussion}

All cooling strategies show a significant reduction of the cooling time and cooling rates, compared with the uncooled reference weld (Table 2). The highest efficiency shows with the water bath cooling. Here the $t_{8 / 5}$ time as well as the $100{ }^{\circ} \mathrm{C}$ cooling time are the lowest. Negative effects on the process stability were not observed.
Although the highest cooling effects were achieved with water bath cooling, it needs to be taken into account that the sample geometry was highly optimised for this cooling strategy. The distance between molten pool and water was minimal from both sides of the substrate plate. For the manufacturing of larger workpieces and more massive structures, multiple welds have to be placed beside each other and the distance between water level and molten pool will be larger. In this case, the distance between weld seam and water bath might vary, which is why direct cooling of the deposited weld seam is expected to be more effective for more complex workpieces.

The cooling with high-pressure air showed slightly lower cooling rates, compared with the water bath cooling, but there is still a high impact, especially on the $100^{\circ} \mathrm{C}$ cooling time. As the cooling starts, after the layer is deposited, the $t_{8 / 5}$ time should be equal to the uncooled reference weld. The reason why the $t_{8 / 5}$ time was affected by the ex situ cooling is that the weld ended and the cooling started, while material in the measuring point was still within the $t_{8 / 5}$ temperature range. This effect is depicted in a detailed view of the $t_{8 / 5}$-cooling curve, as it follows exactly the reference measurement and starts to drop faster instantly after the weld ended (Fig. 10).

One disadvantage of the high-pressure air cooling is that it is disturbing the shielding gas atmosphere of the welding process. Therefore, it can be used only after depositing the welding layer. Furthermore, high-pressure air is expensive, compared with the other cooling mediums and therefore might have a negative effect on the process profitability.
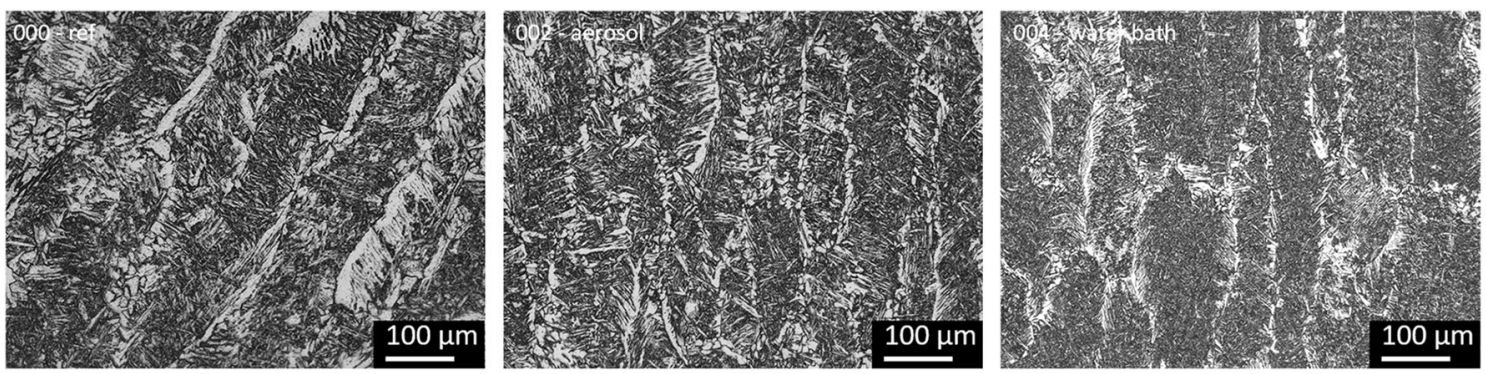

Fig. 5 Comparison of the microscopic cross sections of uncooled (left), aerosol (middle) and water bath welds (right) 
Fig. 6 Comparison of the macroscopic cross sections of the double-welded specimens
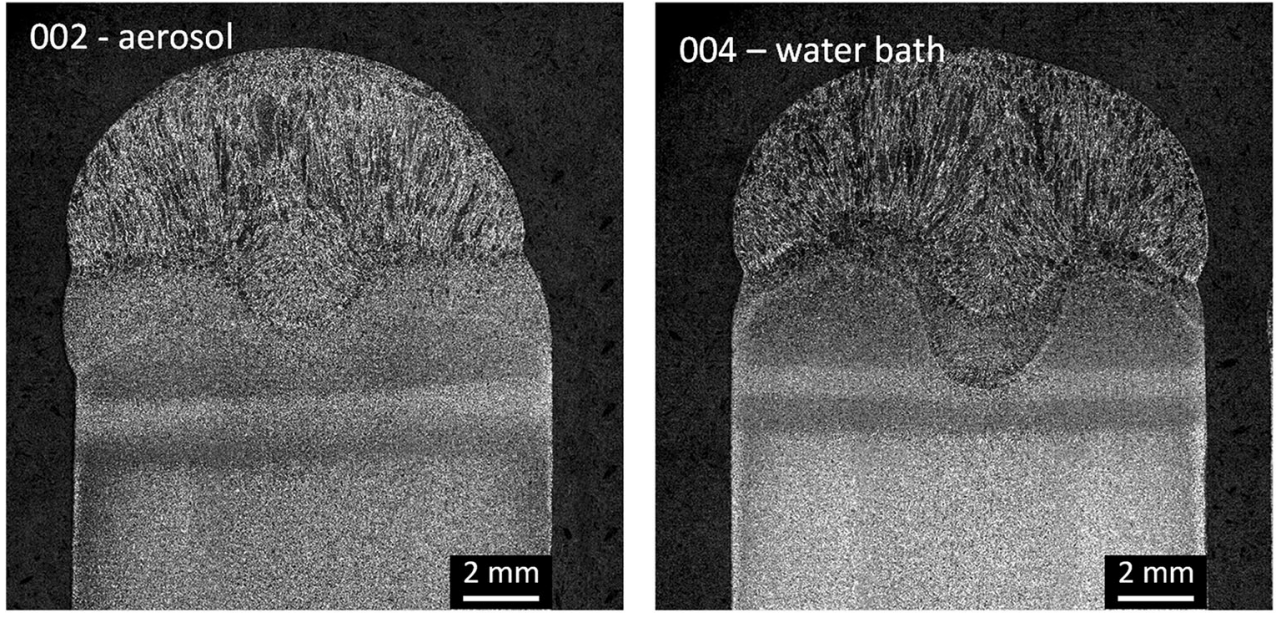

For a combination of in situ cooling and top weld seam cooling, aerosol cooling was investigated. Here, the cooling rates were comparable to the high-pressure air cooling with a $t_{8 / 5}$ time of $12.2 \mathrm{~s}$ and a $100{ }^{\circ} \mathrm{C}$ cooling time of $63.9 \mathrm{~s}$. As discussed before, the advantage of aerosol cooling would be that it does not disturb the shielding gas atmosphere as strongly as the high-pressure air cooling does and therefore can be applied in situ, during the deposition process. Regarding the $100{ }^{\circ} \mathrm{C}$ cooling time, the cooling effect is not as strong as expected. The reason for this might be that the high-pressure air cooling generates more turbulence around the wall-shaped sample and therefore cools down the complete sample more effectively by forced convection. The aerosol cooling, on the other hand, has its highest impact on the top side of the weld seam, where the temperature is high and the vaporization enthalpy of the water has its highest cooling effect. Since the biggest part of the sample has a surface temperature below $100{ }^{\circ} \mathrm{C}$, the cooling effect of the relatively soft aerosol jet seems to be lower, compared with the high-pressure air cooling.
The drops in the temperature curve of the aerosol-cooled weld can be explained by water droplets which condensate on the thermocouple and run down to the measuring point, where they establish a temporary second electric circle and disturb the measuring signal. The plateau can be explained with the thermocouple itself covering the measurement spot from the aerosol jet when being passed.

The results of the measured temperature curves correlate with the microscopic analysis, as well as with the hardness tests. A slight growth in dendrite size is observed, correlating with an increasing $t_{8 / 5}$ time. In addition, the hardness of the weld material is highest for the water bath-cooled sample and lowest for the uncooled sample, while the hardness of the aerosol sample lies in-between. This shows that both in situ cooling methods are capable of influencing the solidification process and the crystal structure. The samples showed similar penetration depths, although the cooling conditions varied. A slight increase in penetration depth for the water bath could be explained by the changed heat dissipation conditions but needs to be investigated more closely for giving a valid explanation.
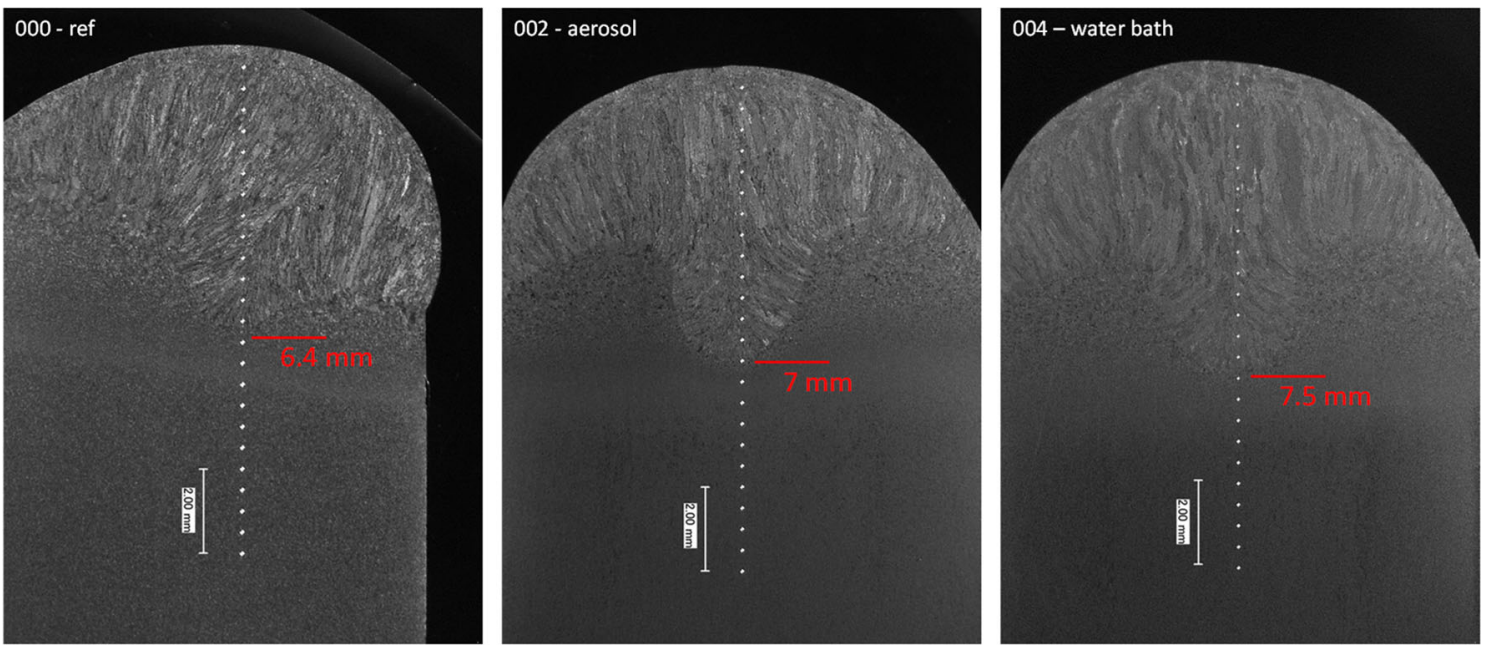

Fig. 7 Positions of the Vickers hardness measurement lines on the single-welded specimens. The estimated position of the fusion lines is marked in red 
Fig. 8 Results of the Vickers hardness measurements on the single-welded specimens

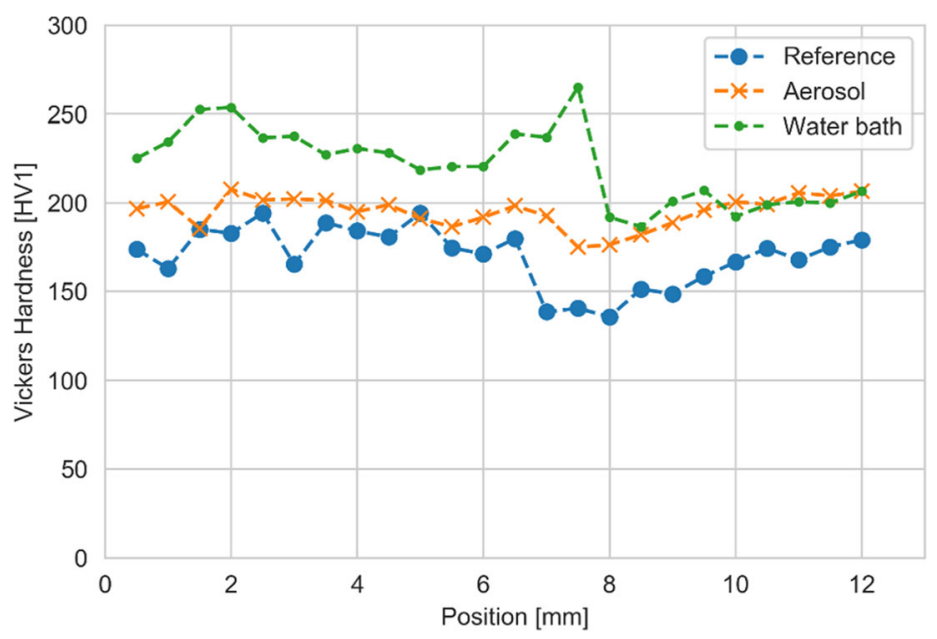

\subsection{Summary}

Different active cooling strategies for wire and arc additive manufacturing have been investigated within the scope of this paper. The evaluation of the cooling methods was carried out by thermal measurements using thermocouples. In addition, the microstructure was investigated in cross sections and the hardness of the deposited weld seams and the heat-affected zone was measured by Vickers hardness tests. In comparison with the uncooled GMAW process, a strong effect on the cooling rates is observed for all three cooling methods.

The water bath cooling method showed highest cooling effect regarding the $100{ }^{\circ} \mathrm{C}$ cooling time $(38.1 \mathrm{~s})$ and the $t_{8 / 5}$ time $(7.1 \mathrm{~s})$, followed by the high-pressure air cooling $(75.7 \mathrm{~s} /$ $12.6 \mathrm{~s})$ and the aerosol cooling (63.9 s/12.2 s). The cooling efficiency seems to be positively influenced by the sample geometry, which allows highly efficient cooling from both sides of the weld seam. Furthermore, welding in a water bath constrains the degrees of freedom of the manufacturing process because the manipulation of the workpiece during the printing process gets more difficult.

High-pressure air cooling seems to be an efficient way of globally cooling down the complete structure. However, as the cooling should only be applied when the welding arc is turned off, it is not possible to affect the $t_{8 / 5}$ times.

The aerosol cooling shows good results regarding the $t_{8 / 5}$ time and the $100{ }^{\circ} \mathrm{C}$ cool down time. The advantage here is

Table 2 Calculated $t_{8 / 5}$ cooling times and $100{ }^{\circ} \mathrm{C}$ cooling times

\begin{tabular}{lll}
\hline Cooling method & $t_{85}$ time $(\mathrm{s})$ & $100{ }^{\circ} \mathrm{C}$ Cooling time $(\mathrm{s})$ \\
\hline GMAW reference & 21.3 & 700.2 \\
Water bath cooled & 7.1 & 38.1 \\
High-pressure air cooled & 12.6 & 75.7 \\
Aerosol cooled & 12.2 & 63.9 \\
\hline
\end{tabular}

Fig. 9 Results of the Vickers hardness measurements on the doublewelded specimens 


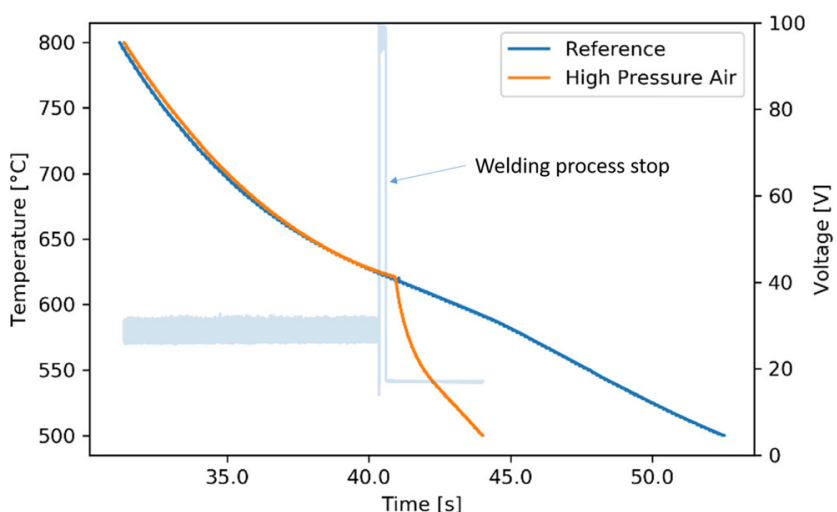

Fig. 10 Detailed view of the cooling curves of uncooled and highpressure air-cooled welds. The process voltage of the high-pressure aircooled GMAW process is plotted in light blue to show that the process end correlates with the starting time of the air cooling

that it can be applied in situ during the welding process and therefore allows to affect the $t_{8 / 5}$ time.

In general, a combination of high-pressure air cooling and aerosol cooling could be an efficient strategy to reduce process idle time and influence the phase transformation behaviour. As many materials are prone to hydrogen or oxygen contamination, other process media will be investigated in the future.

Acknowledgements Open Access funding provided by Projekt DEAL. The presented investigations were carried out at RWTH Aachen University within the framework of the Collaborative Research Centre SFB1120-236616214 "Bauteilpräzision durch Beherrschung von Schmelze und Erstarrung in Produktionsprozessen" and funded by the Deutsche For-schungsgemeinschaft e.V. (DFG, German Research Foundation). The sponsorship and support is gratefully acknowledged. For the sponsorship and the support, we wish to express our sincere gratitude. Special thanks also go to the companies ESAB and EWM for providing welding consumables and welding equipment.

Open Access This article is licensed under a Creative Commons Attribution 4.0 International License, which permits use, sharing, adaptation, distribution and reproduction in any medium or format, as long as you give appropriate credit to the original author(s) and the source, provide a link to the Creative Commons licence, and indicate if changes were made. The images or other third party material in this article are included in the article's Creative Commons licence, unless indicated otherwise in a credit line to the material. If material is not included in the article's Creative Commons licence and your intended use is not permitted by statutory regulation or exceeds the permitted use, you will need to obtain permission directly from the copyright holder. To view a copy of this licence, visit http://creativecommons.org/licenses/by/4.0/.

\section{References}

1. Williams SW, Martina F, Addison AC, Ding J, Pardal G, Colegrove $P$ (2016) Wire + arc additive manufacturing [online]. Mater Sci Technol 32(7):641-647. ISSN 0267-0836. https://doi.org/10. 1179/1743284715Y.0000000073

2. Ding D, Shen C, Pan Z, Cuiuri D, Li H, Larkin N, Van Duin S (2016) Towards an automated robotic arc-welding-based additive manufacturing system from $\mathrm{CAD}$ to finished part [online]. Comput
Aided Des 73:66-75. ISSN 00104485. https://doi.org/10.1016/j. cad.2015.12.003

3. Wu B, Pan Z, Ding D, Cuiuri D, Li H, Xu J, Norrish J (2018) A review of the wire arc additive manufacturing of metals: properties, defects and quality improvement [online]. J Manuf Process 35:127-139. ISSN 15266125. https://doi.org/10.1016/j.jmapro.2018.08.001

4. Pieh1 KH (1989) Formgebendes Schweissen von Schwerkomponenten. Thyssen Tech Ber 21(1):53-71

5. Dilthey U, Berger C, Million K, Datta R, Zimmermann H, Stein L (2006) Future prospects of shape welding. Specialist articles. Weld Cut 2006(3):164-172

6. Pan Z, Ding D, Wu B, Cuiuri D, Li H, Norrish J (2018) Arc welding processes for additive manufacturing: a review. In: Chen $\mathrm{S}$, Zhang Y, Feng Z (eds) Hg. Transactions on intelligent welding manufacturing. Springer Singapore, Singapore, pp S. 3-S.24 ISBN 978-981-10-5354-2

7. Buchanan C, Gardner L (2019) Metal 3D printing in construction: a review of methods, research, applications, opportunities and challenges [online]. Eng Struct 180:332-348. ISSN 01410296. https:// doi.org/10.1016/j.engstruct.2018.11.045

8. Bandari YK, Williams SW, Ding Ji, Martina F. Additive manufacturing of large scale structures: robotic or CNC systems? In: 26th Solid Freeform Fabrication Symposium, S. 17-25

9. Gao M, Zeng X, Hu Q, Yan J (2009) Laser-TIG hybrid welding of ultra-fine grained steel [online]. J Mater Process Technol 209(2): 785-791. ISSN 09240136. https://doi.org/10.1016/j.jmatprotec. 2008.02.062

10. Folkhard E (1988) Welding metallurgy of ferritic stainless chromium steels with carbon contents below $0.15 \%$. In: Folkhard E (ed) $\mathrm{Hg}$. Welding metallurgy of stainless steels. Springer Vienna, Vienna, pp S. 172-S. 178 ISBN 978-3-7091-8967-2

11. Geng H, Li J, Xiong J, Lin X (2017) Optimisation of interpass temperature and heat input for wire and arc additive manufacturing 5A06 aluminium alloy [online]. Sci Technol Weld Join 22(6):472483. ISSN 1362-1718. https://doi.org/10.1080/13621718.2016. 1259031

12. Derekar K, Lawrence J, Melton G, Addison A, Zhang X, Xu L (2019) Influence of interpass temperature on wire arc additive manufacturing (WAAM) of aluminium alloy components [online]. MATEC Web Conf 269(7):5001. https://doi.org/10.1051/ matecconf/201926905001

13. Da Silva LJ, Reis RP, Scotti A (2018) Concept and validation of near-immersion active cooling approach for WAAM. Indonesia. IIW Commission XII - 2018 IIW Annual Meeting

14. Li F, Chen S, Shi J, Zhao Y, Tian H (2018) Thermoelectric coolingaided bead geometry regulation in wire and arc-based additive manufacturing of thin-walled structures [online]. Appl Sci 8(2): 207. https://doi.org/10.3390/app8020207

15. Shi J, Li F, Chen S, Zhao Y, Tian H (2019) Effect of in-process active cooling on forming quality and efficiency of tandem GMAW-based additive manufacturing [online]. Int J Adv Manuf Technol 101(5-8):1349-1356. ISSN 0268-3768. https://doi.org/10. 1007/s00170-018-2927-4

16. Hackenhaar W, Montevecchi F, Scippa A, Campatelli G (2019) Air-cooling influence on wire arc additive manufactured surfaces [online]. Key Eng \Mater 813:241-247. https://doi.org/10.4028/ www.scientific.net/KEM.813.241

17. Wu B, Pan Z, Ding D, Cuiuri D, Li H, Fei Z (2018) The effects of forced interpass cooling on the material properties of wire arc additively manufactured Ti6Al4V alloy [online]. J Mater Process Technol 258:97-105. ISSN 09240136. https://doi.org/10.1016/j. jmatprotec.2018.03.024

Publisher's note Springer Nature remains neutral with regard to jurisdictional claims in published maps and institutional affiliations. 